\title{
Education and Sustainable development: interplay and implications
}

\author{
Ansgar Belke ${ }^{1}$, Andrei Zenkov ${ }^{2, *}$, and Larisa Sazanova ${ }^{2}$ \\ ${ }^{1}$ Universität Duisburg-Essen, Universitätsstr. 12, 45117 Essen, Germany \\ ${ }^{2}$ Ural State University of Economics, 8 Marta Str., 62, 620144 Ekaterinburg, Russia
}

\begin{abstract}
Universities and other Higher education institutions are more than ever on the cusp of disruptive and radical changes while struggling to keep their traditional remit from falling entirely into the hands of managers and accountants. This paper examines the role of (higher) education in achieving sustainable development goals and addresses the important changes facing higher education from multiple perspectives and divergent cultural viewpoints.
\end{abstract}

\section{Introduction}

In understanding the relationship between education and sustainable development, we have to take into account that both education and development are open concepts and can be filled in with a range of normative positions, as well as being highly contested as regards the empirical evidence to support them. There is uncertainty as to the nature of education and development separately, and further contestation as to the relationship between them [1-3].

The paper will be organized as follows: after an initial discussion of each of the basic concepts of education and sustainable development, there will be an assessment of the metalevel of the forms of relationship that might exist between them. The paper first outlines the dominant conception of education as a driver for sustainable development. This relationship is primarily economic, as represented by human capital theory, but may relate to other spheres too, including the political. Following that, the analysis addresses the idea of education as constitutive of development, involving questions of national status, human rights and human development. The next part of the paper turns specifically to higher education, to define what is meant by it, and to assess the particularities of this level of education in relation to the general arguments outlined. Finally, implications are drawn out for the role of higher education in the Sustainable Development Goals (SDGs).

\section{Education and Development: possible Definitions}

The notions of education and development escape precise definitions. In determining what they are we often smuggle in our views on what they should be. The notions are uncertain not only in terms of the best strategies to bring them about, but in the desired end itself. This

* Corresponding author: zenkow@mail.ru 
section will serve to outline the essential components of each concept and identify the areas of legitimate diversity.

We now start with education. The basic feature of this concept is that it is an intentional process of bringing about learning. Only those activities that have been deliberately designed to bring about learning can be given that name. Most obvious of those activities are those designed within institutions dedicated to that end - schools, universities, and so on (what we can conceive as formal education). But the notion of education is also valid for organized activities outside of these institutions - for example the structured activities provided for trainee car mechanics in a garage (non-formal education). When we come to higher education, the notion is almost exclusively used in the formal sense.

The contestation around education occurs in relation to its ends and means. Since education is an intentional process to bring about learning, it varies according to the intentions in question. The second area of significant contestation is about means. Does competition between schools enhance their quality? Should the curriculum focus on the core subjects of mathematics and first language, or should there be a broader coverage? Unlike the value-based questions outlined above, these questions should be amenable to answering through empirical evidence.

A final point on these questions is that one of the most pernicious tendencies in educational debates is to focus exclusively on the question about means and not about ends. Debates about educational policies at the macro-level, and classroom methods and techniques at the micro-level, often take place under the assumption that all parties are agreed on what the ultimate purposes are, and that all that is left is to work out the strategies for obtaining them. This shows a lack of awareness of fundamental differences of moral and political view; at worse, this can serve to shut down debates about the direction of society, and so to maintain the status quo and the interests of dominant groups [4].

We now turn to the notion of development. Here, the term is used in the sense of development of a society rather than the development of an individual. This concept of development, which is dominant to this day across the globe, sees it as a question of economic growth, along with urbanization, technological sophistication, extended transport and communications infrastructure, the provision of public services (including health and education), and 'modern' political, economic and social institutions. An important part of the evolution of the concept of development has been the progressive emphasis on people: moving from a predominantly infrastructural conception (development as roads, bridges, skyscrapers) - to a human one (participation, skills and good governance). It is this concept that has been most supportive of the notion of education as constitutive of development.

Sustainable development, historically, represents the coming together of the international development and environmental agendas of the post-war period, a supposed win-win between protecting the planet and promoting welfare for all. The Brundtland Report (1987) represented a turning point in global recognition of the environmental crisis and paved the way for the UN Conference on Environment and Development in Rio de Janeiro (1992). The Rio Declaration set the agenda for sustainable development for the years to come, paving the way for the SDGs. Conceptually, sustainable development simply refers to a form of development that will not extinguish itself, and therefore, like the notion of development as a whole, is open to multiple interpretations and uses $[5,6]$.

\section{Education as a Driver of Development}

The most commonly invoked conceptualization of education and development is that they are in a causal relationship, that the former brings about the latter, and the more we invest in the former, the more of the latter we get. Three variants of this approach are outlined below. 
Education and economic growth. The instrumental justification for education is that it acts as a motor for economic activity and prosperity, both at individual and national levels. Central to this position is human capital theory, which asserts that investment in education enhances the productivity of workers, and therefore leads to increased economic returns in the form of salary, and greater growth at the macro-level. The human capital theory has had a central place in the economics of education ever since. The theory has also adapted itself in light of the increasing importance of innovation to the economy - with clear relevance for higher education. In the context of the knowledge economy education has taken on far greater importance than in the industrial age, as a means of training knowledge workers, as well as generating innovation and enterprise [2].

Human capital theory emerged within economics to explain economic growth but was adopted as a normative orientation for education. Governments and supranational agencies found a new justification for investment in education, both public and private, through the economic returns that can be gained.

Education and basic needs. A second range of arguments are those that focus on the basic needs of the population. These arguments have been particularly prominent in international development, given the critical levels of poverty and deprivation in many contexts. The distinction from the human capital drivers is that they do not focus solely on enhanced work opportunities and salaries, but on improvement in living standards through direct impact on health, nutrition and other areas of wellbeing. The main substantiation here is that literacy and other basic knowledge and skills allow populations access to essential information and increase their ability to take up public service opportunities, such as use of health clinics and schools [7].

Citizenship and political participation. The third class of reasons may in some instances be compatible with human capital theory, but in many respects challenges its normative underpinnings. Education has been associated with political ends since the training state bureaucrats in the earliest civilizations, passing through the founding of the first national education systems in Europe from the 18th century, largely for the forging of a national ideology and civil service. Empirical research provides extensive evidence that formal education enhances political understanding and engagement [8].

In recent years, global citizen education has become increasingly prominent, in part due to the globalization, and in part to the cosmopolitan commitments of proponents. This wave has been reflected in the SDGs in which global citizenship education is one of the three priorities of the UN Secretary General's Global Education First initiative (along with putting every child into school and improving the quality of learning).

\section{Development-driven education}

Before ending the treatment of the relationship between education and sustainable development, it is important to highlight the alternative perspective that the latter drives the former. It could be argued that the expansion of education systems is more a result of greater economic activity than a cause of it, given that increased state funds allow for investment in the system, and increased family wealth for investment in children's tuition fees. From the historical perspective, the education in the formal sense is a fruit of development, in that it appeared in societies with surplus agricultural production and bureaucratic needs of emerging statehood. There may also be increasing demand for education as an economy industrializes and reaches post-industrial status, with greater need for knowledge workers. Expansion of higher education system has also been brought about by family desires for status and social mobility. The focus of our paper is primarily on education as the causal agent, given its framing as such in the SDGs and the need to develop closer understandings of the role of learning in the transformation of society. 


\section{Education as constitutive of sustainable development}

The above positions are examples of the straightforward relationship between education and development: namely, that the former causes the latter. However, we may also conceptualize it in another way - that education is development, or at least signals development. This may be because the value attached to education is intrinsic rather than instrumental, or because the existence of educated people or institutions is a symbol of status, or if development is conceptualized as a state of mind or learning. Three of these forms will be outlined below.

Education as national status. One way in which education may be seen to be constitutive of development is in the valuing of educational indicators and institutions as markers of development. The achieving of the goal of universal primary education or gender parity might be seen to confer 'developed country' status, or at least to raise a county's status within the 'developing' category. The status rationale is strong in higher education, particularly as regards flagship institutions and their positioning on international rankings. In recent years, this kind of status competition has taken on a different flavor through the increasing prominence of international learning outcome tests: while there are instrumental rationales for scoring well, there is no doubt that a positive league position is seen to be a good in its own right [4].

Beyond status posturing at the national level, there is also the intrinsic value of education and learning: the existence of an educational indicator (mean years of schooling) within the Human Development Index signals that being educated is constitutive of having a dignified and flourishing life, and not only instrumental in achieving other goals.

Education as a human right. A second form of the relationship is the rights-based approach. According to it, the most important objectives at the international level are to ensure the full upholding of the rights enshrined in international law - the most important in relation to education being the International Covenant of Economic, Cultural and Social Rights (1966) and the 1989 Convention on the Rights of the Child. While there are some differences between them, the main stipulation is for universal, compulsory and free primary education, with weaker guarantees at other levels of education (emphasizing accessibility rather than availability).

According to a rights-based conception, the provision of education is non-conditional it is not justified by economic returns that might accrue (even though these may be desirable), or by any other kind of societal or individual benefit. There is also an instrumental role given to education as a multiplier: education is seen to underpin the exercising of other rights, both in terms of possessing the knowledge and skills to participate in society (voting, accessing healthcare, etc.), and also in understanding the significance of human rights themselves. It is this role of education that has been used as a justification for the compulsory nature of the right to elementary education.

Human development. The term human development is associated with the moves that took place to broaden the conception of development from an exclusively economic basis to encompass the range of facets of value to human life. The indicator associated with this approach is the Human Development Index, which includes longevity and education in addition to GDP per capita - not a full expression of human development, but certainly an improvement on GDP alone.

There are clear implications here for education. Learning is seen to have a dual role within human development frameworks: an instrumental one in developing internal capacities (which together with external circumstances enable full capabilities), and an intrinsic one in which education is valuable in itself $[5,7]$.

Crafting the concept of development. The approaches associated with education as a driver assume that development is a fixed notion, and that the task is to assess how education can move us towards that goal. Yet notions of development are founded on a broad spectrum 
of moral and political views, and these views are to a large extent constructed during our life. Education, therefore, has an important role in influencing what we understand development to be. Universities have the potential to be key players in providing a space for deliberation on conceptions of development, creating new ideas, critiquing flawed conceptions and constituting a hub and clearinghouse for national and global debates.

\section{The other face of education}

In the urgency to advocate for education in a funding landscape of many competing priorities, there is a tendency to simplify educational practices, and gloss over the more pernicious aspects. But formal education can have negative effects: corporal punishment is still widespread in schools, and despite the provisions in the Convention on the Rights of the Child, there is still no full ban on it in schools (Global Initiative to End all Corporal Punishment of Children 2018) [1, 5].

A more subtle form of harm inflicted by education systems is through the reproduction of inequalities. Learning outcomes and exam results are correlated with the socio-economic background of the student. While liberals see this as an unfortunate result of disadvantage in home conditions that must be addressed through social and educational policy, social reproduction theorists interpret it as a necessary feature of capitalism.

There are also cultural dimensions to the potential harm of education. Knowledge, its organization and transmission are culturally specific, and in the multicultural society this leads to the exclusion of some cultural groups.

\section{The peculiarities of higher education}

The points outlined above are valid for all levels of education. However, there are some specificities of higher education that arise from the nature of learning at this level, the ways it is organized and funded, and the opportunities it confers in society. The section will start by outlining what is meant by higher education, before assessing areas in which it converges and diverges with basic education in relation to its role as a driver for, constitutive of or a barrier to development.

Definition. A distinctive aspect of higher education is that its institutions very commonly engage in research or scholarship as well as teaching and learning. This aspect distinguishes it from schools, which engage in the transmission of knowledge, but rarely its production.

The university is characterized by teaching, research and community engagement. Even within the teaching and learning role, there are specificities in contrast to schools. First, the higher education depends on prior learning. This requirement justifies the selection procedures to enter higher education institutions, although admissions tests also serve to filter large numbers of candidates for limited places. A second characteristic of learning in higher education is that it is usually highly specialized. A third characteristic is that higher education is generally extended over time. Finally, in most cases higher education involves a theoretical element. This is not to say that it does not have practical engagement or purposes - in fact, the trends in higher education are exactly towards greater practical application. [9-11]

Common characteristics. Higher education exemplifies the relationship between education and development. It is strongly caught up in the beliefs about education's role in economic growth, in terms of government investment and the calculations of individuals and families. This role has become particularly important in the context of the knowledge economy.

In terms of its constitutive role, higher education historically has been strongly associated with the designs of the nation-state. In the period after the World War II in which many 
countries in Africa and Asia gained independence, national universities were established not only to fill the vacuum in human resources left by the departing powers, and to forge cultural and political unity and strength, but also as a marker of nationhood [10].

Divergences. There are some distinctive features of higher education that affect its relationship with development. The research and community engagement functions of higher education mean that it impacts on society and development not only through the inculcation of learning in students but also directly through the production of knowledge and interaction with other citizens. The university's role in science, technology and innovation has been recognized as central to the challenge of sustainable development.

One fundamental difference in teaching function between higher and basic education is the non-obligatory nature of the former. The optional character of higher education leads to some specific considerations. First, states assume less of a requirement to make higher education available and accessible to citizens. There are few countries that provide universal free-of-charge higher education, and it is becoming increasingly prevalent even for public universities to charge fees, with state funding focusing on the most disadvantaged or in backing loan schemes. There is also a strong assumption that learners should be free to choose what they want to study, and in some cases decide on the pace and sequence of those studies - features rarely present in basic education.

\section{Implications of the education-development link}

What are the implications of these considerations for the central question - the role of higher education in the SDGs? Supporting the conception of education as a driver of sustainable development, the natural conclusion would be simply to go about the business of strengthening and extending our university systems, campaigning for funding and working to ensure effective implementation. This linear, instrumental reasoning for education is dominant at the international level and in the policies of governments.

The problems with the above are not only that they focus exclusively on the direct benefits of education, but also that in some cases they assume that these impacts occur automatically as a result of increasing the length of time or investments in the education system. However, it is now commonplace in educational circles to acknowledge that it is learning outcomes and not time in school that bring positive influences.

The linear reasoning fails to acknowledge the ways in which the education system itself is conditioned by the external factors - the most obvious being the amount of funding that is available for it. There is also an aspect in which education is constitutive of development: that developing as a society is about learning, that the development is not outside of the human beings that comprise a society, and instead resides in their level of knowledge, understanding and skill. Education can be seen not only as instrumental in bringing about a particular kind of society, but as an arena of society in its own right, thus involving questions, for example, not only of how it might produce democratic citizens, but also how it might express democracy in its own workings.

It is completely inadequate to simply promote more higher education across the world. It matters what kind of higher education is developed and how it is distributed. For the most part, it is assumed that if an institution can attract students and ensure completion of their degrees then it has succeeded. Consequently, affordability has become the slogan of development agencies in their approach to higher education development: getting as many students as possible through at the least possible cost. Despite the apparent social justice appeal of this approach, not to mention its desirability in addressing the significant funding shortfalls, it is dangerous as it fails to acknowledge the disparities in quality of provision, and the possibilities that many forms of higher education are providing little in the way of meaningful learning for their students $[9,10]$. 


\section{Conclusions}

There is a contradiction between the proposed role of higher education in fostering sustainable development, protecting the environment and reducing poverty, and the forms of higher education supported - ones which frequently foster stratification of systems leading to lower quality provision for the least advantaged, as well as promoting irresponsible development leading to exploitation of workers and destruction of the natural environment. While the emphasis of international agencies on innovation is very welcome, this notion is too often identified only with the use of technology in delivery of higher education services. Technological developments in higher education as in other sectors are promising, but they are one of forms of needed innovation and cannot provide a solution to all challenges.

The most important relationship between education and sustainable development is that the former determines our understanding of the latter. It is important that we foster the deliberative space that exists in Higher education institutions and deepen the enquiry that takes place so as to make reflexive and democratic our conception of development. But ultimately these processes interact in a cyclical manner, with education and development constantly conditioning and forging each other. Our task is to make the cycle enriching and generative, rather than reproductive and destructive.

\section{Acknowledgements}

This work was supported by a grant from the Russian Foundation for Basic Research, project No. 19-012-00199A.

\section{References}

1. U. Azeiteiro, J.P. Davim, Higher education and sustainability: opportunities and challenges for achieving sustainable development goals (Taylor \& Francis, 2020)

2. S.K. Stratton, R. Hagevik, A. Feldman, M. Bloom, Educating Science Teachers for Sustainability (Springer International Publ. Switzerland, 2015)

3. G. Nhamo, V. Mjimba, Sustainable Development Goals and Institutions of Higher Education (Springer Nature Switzerland, 2020)

4. J. Valsiner, A. Lutsenko, A. Antoniouk, Sustainable Futures for Higher Education: The Making of Knowledge Makers (Springer International Publ., part of Springer Nature, 2018)

5. K. Shephard, Higher Education for Sustainable Development (Palgrave Macmillan, 2015)

6. T. McCowan, Higher Education for and beyond the Sustainable Development Goals (Palgrave Macmillan, 2019)

7. M. Peris-Ortiz, J.M. Merigó Lindahl, Sustainable Learning in Higher Education: Developing Competencies for the Global Marketplace (Springer International Publ. Switzerland, 2015)

8. K. Mulder, Int. J. of Sustainability in Higher Education, 5 (2004)

9. A.V. Zenkov, J. of Quantitative Linguistics, 25 (2018)

10. A.V. Zenkov, Computer Research and Modeling, 9 (2017)

11. A.V. Zenkov, First International Volga Region Conf. on Economics, Humanities and Sports (FICEHS 19). Paris, Atlantis Press, Adv. in Economics, Business and Management Research 114, (2019) 